\title{
Observation of the Effect of the Application of Neurodynamic Principles in Lumbar Nerve Entrapment Syndrome Therapy
}

\author{
Peter Hermel ${ }^{1}$, Jozef Živčák ${ }^{2}$, Gabriela lžaríková ${ }^{3}$ \\ Non-State Rehabilitation Health Facility Werferova 3, Košice, Slovak Republic \\ Department of Biomedical Engineering and Measurement, Faculty of Mechanical Engineering, Technical University of Košice, Letná 1/9, Košice \\ Department of Applied Mathematics and Informatics, Faculty of Mechanical Engineering, Technical University of Košice, Letná 1/9, Košice, Slovak \\ Republic
}

Abstract:The article focuses on the evaluation of special therapy with neural mobilization aimed at observation of the effect of neural mobilization on a subjective parameter - pain of patients who have been diagnosed with lumbar nerve entrapment syndrome. Neurodynamic disruption is an inseparable part of clinical manifestation connected with pathological processes and changes in strain in periradicular and perineural area manifested in symptomatology of nerve roots. For the purposes of clinical practice, it is necessary to define the meaning of changes in neural mobility and differentiate between individual natures of symptoms. The differentiation of these damages lies in the specification of the share of micro sensitivity of nervous tissue in the whole image of neuropathic pain.. For purposes of the analysis results of a research realised in a rehabilitation facility were used. Standardized tests modified for the aim and tasks of the research according to specific set of rules to get real data were used. The key points of the research were pain intensity, the scale of painless motion immediately after neural mobilization in Laségue's test and SLUMP test, and the phenomena of pain centralization assessed according to classification for spinal disorders according to Quebec Task Force of Spinal Disorders. Nerve mobilization techniques with standard rehabilitation were applied to patients. Pain intensity was evaluated by a ten-point Visual Analogue Scale. The results achieved point out the increase in efficiency of medical rehabilitation via additional application of neural mobilization which, thanks to its comprehensive method, enables to make the process of medical rehabilitation more efficient, better, and faster.

Keywords: Lumbar Nerve Entrapment Syndrome; neuropathic pain; mechanosensitivity of the nervous system; neurodynamic tests; Quebec Task Force of Spinal Disorders; neural mobilization.

\section{Introduction}

\subsection{Nerve Damage}

Lower back pain is a significant health and socio-economical problem of the modern society. 60 - $80 \%$ of the overall population has at least once experienced pain in their lower back at some point in their lives $[12,15]$.

Approximately $40 \%$ of lower pain back was caused by damage of a disc between the vertebrae, which causes biomechanical changes and potential compression of nerve roots, manifested in decrease of conductive function, i.e. entrapment syndrome [14].

Peripheral neuropathic pain is defined by the International Association of the Study of Pain (IASP) as a pain initiated or caused by primary lesion or dysfunction of peripheral nervous system [16]. Upon the impact of pathological stimuli and their passing to the nervous system, a chain of reactions is created resulting in damage of nerve roots or 
peripheral nerves by mechanical and/ or chemical stimuli $[8,17]$. Clinical manifestations of peripheral nerve damage at the emergence of pain are often assessed through positive and negative symptoms viewpoint. Positive symptoms reflect abnormal level of irritation in the nervous system and include pain, paresthesia, dysesthesia and spasms. Negative symptoms cause reduced convulsion of impulses in nervous tissues and include hypesthesia or anesthesia and weakness $[2,3]$.

Neuropathic pain is often on the top of overall spinal and peripheral locomotor dysfunctions, therefore, somatic symptoms of peripheral neuropathic pain secondarily lead to the dysfunction of musculoskeletal apparatus, include increased mechanosensitivity in nervous tissues, combined with respective disabilities in the ambient structures of musculoskeletal apparatus, while the severity of lesion determines the deficiency of impulses $[5,18]$.

\subsection{Neural Diagnostics}

To assess changes in neural mobility, neurodynamic tests where elasticity of nervous tissue is tested, are used. The aim of these tests is to determine the nature of the damage and irritability of nervous system. The primary aim of nerve roots diagnostics is to narrow the intervertebral space by combined provocative movements and to create tension of nervous tissues (neurodynamic tests), which have become more responsive to their sensibilization caused by external irritation, notably herniation of a disc [11]. By a specific sequence of movements, mechanical nerve sensitivity is evaluated. Mechanical irritation of peripheral nervous structures is manifested in pains with characteristic projection transferred in dermatomes identical with behaviour of nerve roots, or also without the identity with the scheme. Patients list paresthesias, or dysesthesias with possible sensory or motoric deficiency.

In the initial phases of compression, patients describe mostly sharp, shooting pain. With longerlasting compression, or growing pressure, the nature of the pain gradually changes to blunt and diffused. The first symptome of disability of conduction nerve function is the decrease of conduction conveyed by myelinated nerve fibres, which are most sensitive to compression. Clinically, vibration sensitivity deficiency is manifested first. With time and intensity of compression increased, reduction of tendon and periosteal reflexes and muscle strength occur. Finally, reduction of sensitivity, first of mild, tactile nature, later of deep, conveyed by nociceptors. Due to overlap of dermatomes and myotomes and substitutional supply of muscles and skin from more roots, the scale of neurological deficit is smaller and not always clear. During clinical examination conducted by inspectors, a finding of antalgic posture with the aim of relief of mechanical tension of damaged nerve tissues. Engagement of antalgic posture lies in the attempt to shorten and immobilize the damaged limb or segment. The lower limb reacts mostly with flectional posture with pelvic torsion. The spine easily assumes flectional posture with side motion, resulting in relief of the disc and decrease of root pressure. Approximately $80 \%$ of acute posterolateral disc herniation cases show lateral motion of spine against the pelvis from the lesion side $[18,17]$

Results of CT and MRI display methods which describe localization and level of nerve compression or clarify mechanisms of pressure; and data from EMG, which verify the diagnosis and the level of nerve damage are relied upon in the examination process. The EMG examination leads to a discovery of extended latension, as well as steady denervation potentials with more serious damages [7, 9, 19]. The overall check of changes in neural dynamics, its correlation with results of diagnostic and display examinations, along with clinical picture and pain presentation create the basis for application of neural tests and neural mobilization.

For the purposes of comprehensive approach towards therapy, it is practical to state the following classification for spinal disorders according to Quebec Task Force of Spinal Disorders [1]. The classification goes as follows:

- pain without radiation,

- back pain with proximal extremity radiation,

- back pain with distal extremity radiation,

- lower limb pain greater than back pain,

- back pain with radiation with presence of neurologic signs,

- post-surgical status (<6 months),

- chronic pain syndrome.

This classification is relevant also for peripheral disorders, since integration of a signal from periphery where the disorder is centralized happens on the spinal level.

\subsection{Therapy - neural mobilization}

Mobilization of the Nervous System is an approach of functional treatment of pain. The 
method is founded on affecting pain physiology by mechanical manipulation of nervous tissues and non-neural structures in an area of the Nervous System [8].

Techniques for the mobilization of nervous tissue consist of passive or active movements focused on recovering the Nervous System's ability to tolerate normal pressure, frictional and tensile force, typical for everyday and sports activities, i.e. to reduce mechanosensitivity of the Nervous System and recover its usual movement abilities. Neural mobilization has a positive effect on symptoms thanks to improvement of intraneural circulation, axoplasmatic flow, viscoelasticity of neural connective tissue and reduction of sensitivity of AIGS - abnormal impulse generating sites $[3,4,18]$.

When applying pressure, or movement of neural structures it is necessary to take specific level of elasticity of nerve structures into account. Anatomical structure of nerve structures enables both intraneural and extraneural accommodation. Mechanism of intraneural extension lies in shifts between individual nerve fibres and their endoneurium. The extraneural extension is provided by shifts between epineurium and perineural structures $[4,10,11]$. Principles of neural tension and neural shift are applied in the form of physiological movements in smaller or larger amplitudes in the necessary time duration and frequency, depending on the level of irritation $[10,11]$. In the acute phase, when irritation is greater, it is recommended to apply therapy of neural shift, and later after the symptoms have been relieved, pressure therapy is recommended. Therapy should be carried out painlessly, with regards to barriers in soft tissue and reflex spasm, according to constant analysis of patient's tolerance. Modification of neural mobility or improvement of kinetic pressure tolerance lead to decrease of painful irritation and relief of overall symptoms $[13,17]$.

\section{Methodics}

For purposes of the analysis results of a research realised in a rehabilitation facility were used. Standardized tests modified for the aim and tasks of the research according to specific set of rules to get real data were used. Individual approach in a form of a questionnaire was used for collection of data to learn about the course of the disease better and to carry out a thorough clinical examination of the basic diagnosis of lumbar nerve entrapment syndrome. After acquiring their informed consent, patients were guaranteed full discretion for their data and results of the tests. Discard of patients' medicines was not part of the testing process, since ethical principles of the research do not allow it. The key points of the research were pain intensity, the scale of painless motion immediately after neural mobilization in Laségue's test and SLUMP test, and the phenomena of pain centralization assessed according to classification for spinal disorders according to Quebec Task Force of Spinal Disorders. Nerve mobilization techniques with standard rehabilitation were applied to patients. Pain intensity was evaluated by a ten-point Visual Analogue Scale.

Pain scale:

0 - no pain,

$1 \div 3$ - mild pain,

$4 \div 6$ - moderate pain,

$7 \div 10$ - severe pain.

Results of the effects of the therapy are assessed by comparing results (pain intensity according to VAS, Laségue's test, SLUMP test) between 3 groups $-A, B$, and $C$.

\section{Division to three groups:}

A - input health condition (carried out at the entry medical examination before starting the therapy), $B$ - health condition during the therapy (carried out during the therapy),

$\mathrm{C}$ - health condition after ending the therapy

(carried out after finishing the therapy).

Differences between groups can be observed in a graphic representation; for comparison of various files a non-parametric test, such as Kruskal-Wallis test (non-parametric ANOVA) which shows whether the results are statistically significant are used. Usage of ANOVA was not possible in this assessment, since conditions necessary for its usage were not met.

The Kruskal-Wallis test by ranks, or One-way ANOVA on ranks is a non-parametric method for testing whether samples originate from the same distribution. It is used for comparing two or more independent samples of equal or different sample sizes. Since it is a non-parametric method, the KruskalWallis test does not assume a normal distribution of the residuals, unlike the analogous one-way analysis of variance. Null hypothesis is that the medians of all groups are equal, and the alternative hypothesis is that at least one population median of one group is different from the population median of at least one 
other group.

The following hypotheses are observed:

- H01: pain intensity does not depend on therapy, or more precisely, all samples originate from the same distribution,

- H02: result of the SLUMP test does not depend on therapy, or more precisely, all samples originate from the same distribution,

- H03: result of Laségue's test does not depend on therapy, or more precisely, all samples originate from the same distribution,

- H04: result of the test on spinal disorders does not depend on therapy, or more precisely, all samples originate from the same distribution.

\subsection{Characteristics of the Respondents}

Characteristics of the group - age, sex - table of abundance graphic charts

After evaluating the survey and analysing the acquired information, answers of 159 respondents - patients, were used for further analyses, namely patients who underwent the survey on the effectiveness of rehabilitation treatment of neural mobilisation with addition of standard physiotherapy during outpatient treatment at basic diagnosis of lumbar nerve entrapment syndrome. The survey compared and assessed the difference between health condition and observed parameters with patients before, during rehabilitation and after undergoing all rehabilitation procedures. The observed group was composed of 94 women and 65 men, their age structure is found in Table 1, Chart 1. Patients over 50 were excluded from the survey. It is natural that the largest number of patients was of age 36 to 40 - 69 respondents, representing 43,4\% of the whole set. This group consisted of 39 women, representing $24,53 \%$ of all respondents, $41,49 \%$ of all women, or $56,52 \%$ of all respondents (patients) of age 34 to 40 . The most numerous group consisted of 30 men, representing $18,87 \%$ of all respondents, $46,15 \%$ of all men, or $43,48 \%$ of all respondents (patients) of age $36 \div 40$.

Table 1: Structure of the study group

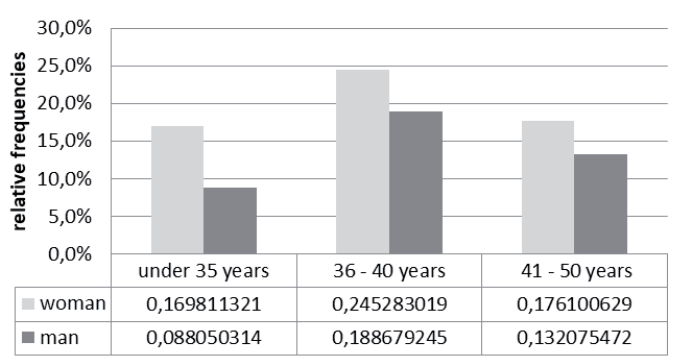

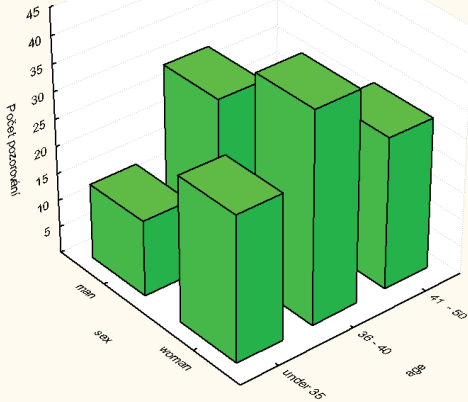

Figure 1: Bivariate histogram of the study group

\subsection{Evaluation of Pain Intensity according to VAS}

Pain intensity can be quantified via visual analogue scale or numerical scale from 0 to 10, where 0 represents no pain and 10 represents the worst pain imaginable. This kind of measuring enables monitoring the change in condition and improvement in treatment. The informative value of the pain lies in identifying the nature of changes in function, as well as the stage of the disease.
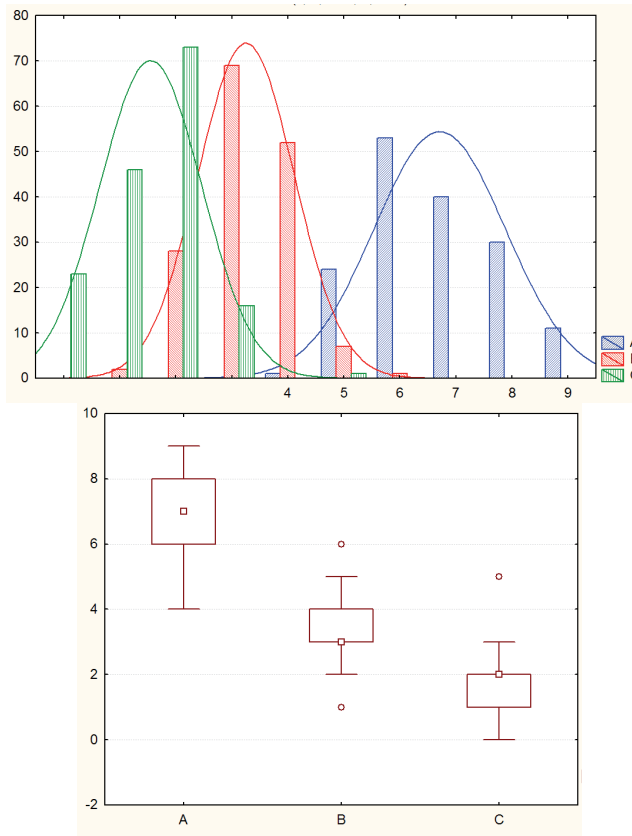

Figure 2: Graphical evaluation of pain intensity

Graphic representation (Fig. 2.) of acquired data clearly shows that there exist differences between individual groups, notably pain intensity which, according to VAS is highest at the beginning, before 
the therapy, and the lowest after ending the therapy. To compare the individual sets a non-parametric test such as Kruskal-Wallis test is used. The test is used to test the hypothesis:

H01: pain intensity does not depend on therapy, more precisely, all samples originate from the same distribution, H11: non HO.

Table 2: Kruskal-Wallis test - pain intensity

\begin{tabular}{|l|l|l|l|}
\hline Prom & \multicolumn{3}{|l|}{$\begin{array}{l}\text { Kruskal-Wallis ANOVA by Ranks } \\
\text { Independent (grouping) variable: therapy } \\
\text { Kruskal-Wallis test } H(2, N=477)=391.1931 \\
p=.0000\end{array}$} \\
\cline { 2 - 4 } & CODE & VALID & $\begin{array}{l}\text { Sum of } \\
\text { Ranks }\end{array}$ \\
\hline A & A & 159 & 63100.50 \\
\hline B & B & 159 & 35769.00 \\
\hline C & C & 159 & 15133.50 \\
\hline
\end{tabular}

Result of the test is a p-value, $p=0.0000<$ 0.05 (Table 2.), meaning that the null hypothesis is rejected on the significance level of 0.05 , i.e., there exists a statistically significant difference. Hence, the therapy affects pain intensity evaluated by VAS scale.

\subsection{Evaluation of the SLUMP Test}

Description of the SLUMP test: Patient is seated upright with hands behind his back, after slight slump forward, his head is slightly flexed. After straightening the lower limb on the non-damaged side, the patient adds dorsal flexion of the ankle joint. He extends the damaged limb alternatively while changes in painfulness and its projection into the lower limb and the extension in knee joint are observed. The informative value lies in revealing discogenic lesions and changes in mobility during lumbar pain with/without propagation of the lower limb.

In comparison to Lasegue's test, testing in sitting position with vertical pressure creates higher intradiscal pressure, hence enabling clinical reveal and evaluation of disc protrusion of milder degree.

As it can be seen in Fig. 3., differences between individual groups are minimal. Average values in individual groups are 19.3,-18.5 and -18.4. Whether these results are statistically significant is tested with Kruskal-Wallis test (Table 3).

H02: result of the SLUMP test does not depend on therapy, or more precisely, all samples originate from the same distribution, H12: non HO.

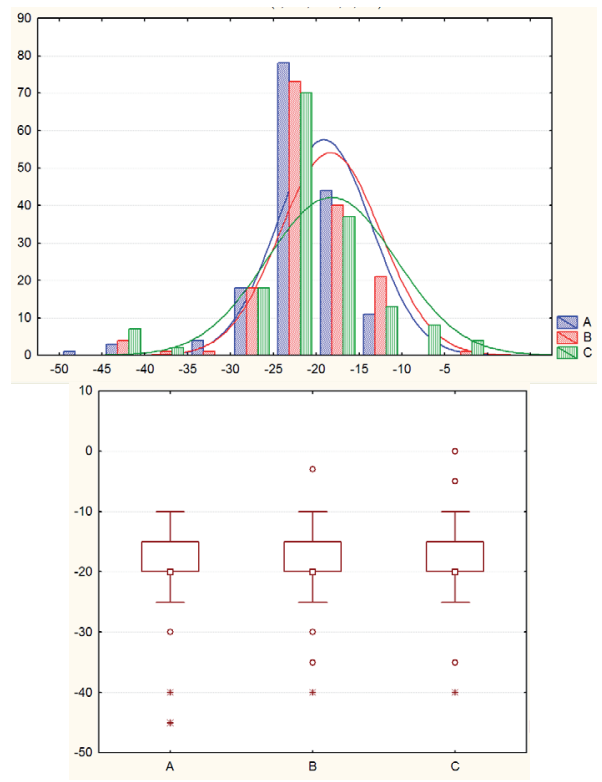

Figure 3: Graphic evaluation of SLUMP test

Table 3: Kruskal-Wallis test - SLUMP test

\begin{tabular}{|l|l|l|l|}
\hline Prom & \multicolumn{3}{|l|}{$\begin{array}{l}\text { Kruskal-Wallis ANOVA by Ranks } \\
\text { Independent (grouping) variable: therapy } \\
\text { Kruskal-Wallis test } H(2, N=477)=1.550552 \\
p=0.4606\end{array}$} \\
\cline { 2 - 4 } & CODE & VALID & $\begin{array}{l}\text { Sum of } \\
\text { Ranks }\end{array}$ \\
\hline A & A & 159 & 36341.50 \\
\hline B & B & 159 & 38820.00 \\
\hline C & C & 159 & 38841.50 \\
\hline
\end{tabular}

The result of the test is a $p$-value, $p=0.4606$ $>0.05$, meaning that the null hypothesis is not rejected on the significance level of 0.05 , i.e. there does not exist a statistically significant difference between the sets. Hence, the therapy does not affect the results of the SLUMP test.

\subsection{Evaluation of the Laségue's Test}

The Laségue's test is considered the key flexing manoeuvre of neural mobility while evaluating discogenic diseases of lumbar spine.

Description of the Laségue's test: Patient is supine. The tested lower limb is held by one hand, while the knee is fixated with the other hand from the top. The passive lower limb is steadily lifted, while pain reaction in lumbar area, occurrence of transferred pain and paresthesia are observed. At the end of the movement, dorsal flexion of the 
ankle or flexion of the neck can be added. A certain degree (angular flexion) of syndrome provocation is registered. Tension in popliteal fossa is considered a normal response.

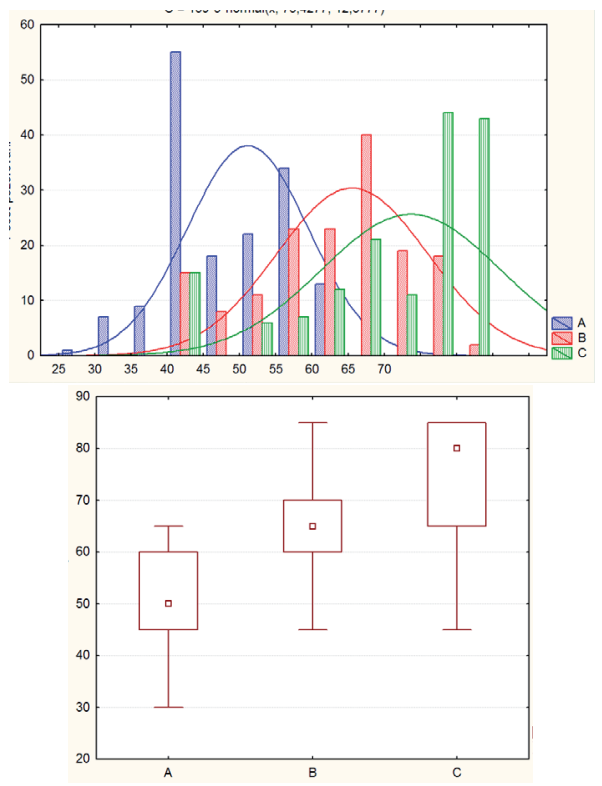

Figure 4: Graphic evaluation of Laségue's test

As it can be seen in Figure 4., there exist differences between individual groups; the highest values are acquired by patients from group $C$ and the lowest from group A. To test these differences, a non-parametric Kruskal-Wallis test is used:

H03: result of Laségue's test does not depend on therapy, or more precisely, all samples originate from the same distribution H13: non HO.

Table 4: Kruskal-Wallis test - Laségue's test

\begin{tabular}{|l|l|l|l|}
\hline \multirow{2}{*}{ Prom } & \multicolumn{3}{|l|}{$\begin{array}{l}\text { Kruskal-Wallis ANOVA by Ranks } \\
\text { Independent (grouping) variable: therapy } \\
\text { Kruskal-Wallis test } H(2, N=477)=211.1664 \\
p=0.0000\end{array}$} \\
\cline { 2 - 4 } & CODE & VALID & $\begin{array}{l}\text { Sum of } \\
\text { Ranks }\end{array}$ \\
\hline A & A & 159 & 18892.50 \\
\hline B & B & 159 & 41208.50 \\
\hline C & C & 159 & 53902.00 \\
\hline
\end{tabular}

Result of the test is a p-value, $p=0.0000<$ 0.05 (Table 4.), meaning that the null hypothesis is rejected on the significance level of 0.05 , i.e., there exists a statistically significant difference. Hence, the therapy affects the results of Laségue's test.

\subsection{Evaluation of Spinal Disorders}

With motion into a certain direction, the phenomena of centralization may occur. It is characterized by withdrawal of symptoms from periphery in proximal direction. Symptoms on the periphery decrease while symptoms on the proximal direction increase. After ending the testing motion, this change must prevail. The motion or position which causes centralization reduces the disorder.

Classification for spinal disorders according to Quebec Task Force of Spinal Disorders, modified for the purposes of evaluation of the phenomena of centralization for the chosen group of respondents:

1. no pain

2. back pain without radiation

3. back pain with proximal extremity radiation

4. back pain with distal extremity radiation

5. lower limb pain greater than back pain

6. chronic pain syndrome

Division of respondents according to spinal disorders and reverence to the individual group can be seen in Table 5, Picture 5.

Table 5: Pivot Table

\begin{tabular}{|l|l|l|l|l|l|l|l|}
\hline \multirow{2}{*}{ Therapy } & \multicolumn{6}{|l|}{ Spinal disorders } & \multirow{2}{*}{$\Sigma$} \\
\cline { 2 - 9 } & 1 & 2 & 3 & 4 & 5 & 6 & \\
\hline$A$ & 0 & 27 & 64 & 55 & 13 & 0 & 159 \\
\hline$B$ & 0 & 40 & 93 & 25 & 1 & 0 & 159 \\
\hline$C$ & 12 & 79 & 53 & 12 & 0 & 3 & 159 \\
\hline$\Sigma$ & 12 & 146 & 210 & 92 & 14 & 3 & 477 \\
\hline
\end{tabular}

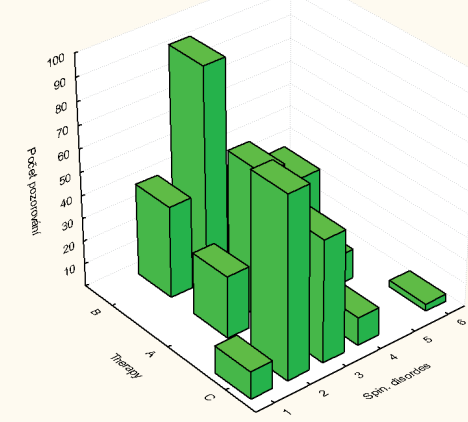

Figure 5: Bivariate histogram of spinal disorders

To evaluate the relation between observed points a test of independence (Pearson Chisquare test) is used. Pearson Chi-square test of 
independence is used to evaluate independence of two sets of categorical data of the same selection.

$\mathrm{HO}$ : Assumes independence of quality features.

$H 1$ : Assumes independence of quality features.

Table 6: Pearson Chi-square test

\begin{tabular}{|l|l|l|l|}
\hline Statist & \multicolumn{4}{|l|}{ Statist: Prom1(6) $x$ Prom2(3) } \\
\hline & Chí-square. & Sv & $P$ \\
\hline $\begin{array}{l}\text { Pearson chi } \\
\text { square }\end{array}$ & 126.4419 & $\mathrm{df}=18$ & $\mathrm{p}=0.0000$ \\
\hline $\begin{array}{l}\text { M-V chí } \\
\text { suare. }\end{array}$ & 128.9618 & $\mathrm{df}=18$ & $\mathrm{p}=0.0000$ \\
\hline
\end{tabular}

The Pearson Chi-square test is 126.4419 with a $p$-value of 0.0000 . Since the $p$-value is less than alpha $=0.05$, the null hypothesis (Rehabilitation and Spinal disorders) is rejected. This can be interpreted by saying that a significant relationship exists between a Rehabilitation and Spinal disorders. Results of Pearson Chi-square test are found in Table 6. Hence, the therapy significantly affects the degree of pain.

\section{Discussion}

In our study, we analysed the results of special therapy using neural mobilization and classical physiotherapy in patients diagnosed with lumbar nerve entrapment syndrome. The goal of treatment in patients with lumbar nerve entrapment syndrome was to reduce pain and allow the patient to return to full movement activity, in the case of athletes to full sport activity. Patients after therapy (after conversion neurodynamic mobilization and classical rehabilitation) reported lower values in the assessment of pain intensity using VAS, the differences in pain intensity averages are statistically significant. Another evaluated parameter, was the range of motion measured by a goniometer when performing standardized neurodynamic tests according to David S. Butler (SLUMP test and Lasséque test). In the SLUMP test, the analysis of the results confirmed the improvement, an increase of the range of motion, but the differences were not statistically significant.

During the Lasséque test, the effect of the same neurodynamic mobilization with classical physiotherapy occurred after the end of the therapy further improvement of the measured values of the range of motion. In the monitored sample of patients included to the research, there was a gradual decrease in pain intensity in DK with a transient increase in pain in the centre.

Since the phenomenon of centralization already represents a small shift of pain in the proximal direction, or a reduction intensity of pain in the periphery, statistical evaluation confirmed a strong dependence between the spinal disorders and changes in spinal disorders.

The duration of the idle regime with treatment options, which also includes therapeutic exercise activity must be balanced, in case of noncompliance we often encounter complications and recurrence of difficulties.

So far, the optimal treatment algorithm and a clear conclusion as to which of the treatment modalities or their combination is the most effective, has been not described.

Degeneration of the intervertebral disc due to normal aging or pathological processes is serious disease affecting many individuals. The main surgical procedures in the treatment related to degenerate disc, are disectomy, fusion, and total intervertebral disc substitution. While these surgical procedures provide relatively good short-term clinical results, and their use also changes biomechanics of the spine, possibly leading to further degeneration of surrounding tissues and intervertebral discs on other segments. Based on research in 2000, Bersmann showed that approximately $35 \%$ of patients need to have surgery within two years, and within one year after surgery, $80 \%$ of patient's non-specific pain in the lower spine.

\section{Conclusion}

The authors focused on emphasising the importance and relevance of chosen methods of therapy via neural therapy with focus on observation of the effect of neural mobilization and on a subjective parameter - pain of patients who suffer from basic lumbar nerve entrapment syndrome. The key points of measurement were pain intensity evaluated via a ten-point visual analogue scale (VAS), scale of painless motion immediately after neural mobilization in Laségue's test and SLUMP test, and the phenomena of pain centralization evaluated according to classification for spinal disorders according to Quebec Task Force of Spinal Disorders. Based on the acquired results, changes in differences in pain intensity, scale of movement, and phenomena of pain centralization with patients before, during and after the rehabilitation were 
statistically evaluated. After ending the whole therapy (overall rehabilitation with addition of neural mobilization) a lower degree of pain, greater scale of painless motion in neurodynamic test, and withdrawal of the phenomena of centralization assessed according to classification for spinal disorders according to Quebec Task Force of Spinal Disorders proved to be statistically significant.

\section{References and Notes}

1. BARON R, 2000 Peripheral neuropathic pain: From mechanisms to symptoms. The Clinical Journal of Pain 16 (Suppl.) 12-S20

2. Bove G, Ransil B, Lin H, Leem J 2003 Inflammation induces ectopic mechanical sensitivity in axons of nociceptors innervating deep tissues. Journal of Physiology 90 1949-1955.

3. Butler D, 1991 Mobilisation of the Nervous System. Churchill Livingstone, Edinburgh, ISBN: 0-443-04400-7.

4. Butler D, 1998 Adverse mechanical tension: a model for assessment and treatment Commentary Adverse neural tension reconsidered. Australian Journal of Physiotherapy Monograph 3: 13-17

5. BUTLER D, 2005 The neurodynamic techniques. Adelaide. Australia: Noigroup Publications.

6. HAGOVSKÁ M, 2011 Prehlad neurológie pre fyzioterapeutov. Vysokoškolský učebný text pre fyzioterapeutov. Knihy Hanzluvka. Košice. ISBN 978-8089546-01-5

7. HAGOVSKÁ M, 2013 Konzervatívne možnosti liečby chronických bolestí chrtbtice aplikáciou mechanickej diagnostiky a terapie. Košice. ISBN: 978-80-971433-8-1

8. Jean Pierre Barral, Alain Croibier 2005 Manual Therapy for the Peripheral Nerves. Churchill Livingstone .1st Edition. ISBN: 978-0443103070

9. JENDRICHOVSKÝ M, 2011 Neuro-muskulo-skeletálny koncept diagnostiky pre fyzioterapeutov I. Stará L’ubovña. ISBN 978-80-970714-3-1

10. JENDRICHOVSKÝ M 2013 Neuro-muskulo-skeletálny koncept diagnostiky pre fyzioterapeutov II. Stará Lubovňa. ISBN 9788097143350

11. JENDRICHOVSKÝ M 2008 Ovplyvňovanie mechanosenzitivity nervových tkanív metódou neurálnej mobilizácie. Rehabilitace a Fyzikální Lékařství, Praha, No. 3: 114-121

12. KOPEC JA, SAYRE E C, ESDAILE J M, 2004 Predictors of back pain in a general population cohort. Spine 29, 70 -78.

13. MAITLAND G 2001 Maitland's Vertebral Manipulation: 6th edition Oxford, Buttersworth Heineman, ISBN-10: 0750624477

14. MAMIKO NOGUCHI, CHAD E GOOYERS, THOMAS KARAKO-
LIS, KIMIHIRO NOGUCHI, JACK P, 2016 Callaghan Is intervertebral disc pressure linked to herniation?: An in-vitro study using a porcine model. journal of biomechanics. June 14 Volume 49. Issue 9. 1824-1830

15. MAUL, I., LAUBLI, T., KLIPSTEIN, A., KRUEGER, H., 2003 Course of low back pain among nurses: a longitudinal study across 8 years. Occup. Environ. Med. 60, 497e503.

16. MERSKEY.H.,BOGDUK.N. 1994 Classification on chronic pain: Descriptions of chronic pain syndromes and definitions of pain terms .2nd ed. Seattle. International Association for the Study of Pain

17. ROBERT J. NEE, DAVID BUTLER. 2006 Management of peripheral neuropathic pain: Integrating neurobiology, neurodynamics, and clinical evidence. Physical Therapy in Sport 7 , 36-49

18. SHACKLOCK, M. 2005 Clinical neurodynamics: A new system of musculoskeletal treatment. Edinburgh: Elsevier/Butterworth Heinemann. ISBN- 0750654562

19. TAKÁČ, P 2003 Klinická propedeutika v rehabilitácii. Skriptá Trnavskej univerzity, Slovak Academic Press, 219s. ISBN 8089104-16-9

20. TAKÁČ, P. 2006 Klinická propedeutika $\vee$ rehabilitácii pre poslucháčov lekárskej fakulty. Košice: Vydavatel'stvo UPJŠ v Košiciach. 230s. ISBN: 80-7079-634-9 